\title{
Bromfenac Sodium
}

National Cancer Institute

\section{Source}

National Cancer Institute. Bromfenac Sodium. NCI Thesaurus. Code C65272.

The sodium salt form of bromfenac, a nonsteroidal anti-inflammatory drug (NSAID) with analgesic and anti-inflammatory activities. Upon ophthalmic administration, bromfenac binds to and inhibits the activity of cyclooxygenase II (COX II), an enzyme which converts arachidonic acid to cyclic endoperoxides, precursors of prostaglandins (PG). By inhibiting PG formation, bromfenac is able to inhibit PG-induced inflammation, thereby preventing vasodilation, leukocytosis, disruption of the blood-aqueous humor barrier, an increase in vascular permeability and an increase in intraocular pressure (IOP). 